\title{
O ENSINO DE BIOLOGIA NA EJA A PARTIR DA PROPOSTA CURRICULAR DO ESTADO DE RORAIMA
}

\section{THE TEACHING OF BIOLOGY IN THE EJA FROM THE CURRICULAR PROPOSAL OF THE STATE OF RORAIMA}

\author{
Creone Vieira Silva ${ }^{1}$ \\ Sandra Kariny Saldanha de Oliveira²
}

RESUMO: A pesquisa que embasou este artigo teve como objetivo geral analisar o ensino de Biologia a partir da Proposta Curricular de Roraima para a Educação de Jovens e Adultos EJA. Para a realização da pesquisa adotou-se o método qualitativo, a coleta de dados foi feita com a diretora da DIEJA da Secretaria Estadual de Educação - SEED/RR e com nove professores de Biologia. A entrevista teve como finalidade obter informações sobre a Proposta Curricular da EJA. O questionário para os professores objetivou conhecer o perfil profissional, os métodos e técnicas utilizados no processo ensino e aprendizagem. A pesquisa buscou responder a indagação: $\mathrm{O}$ conhecimento da Proposta Curricular é um passo para a boa prática pedagógica?Os resultados mostraram que a EJA encontra-se em um momento de dificuldades quanto à oferta de condições de trabalho, pois falta infraestrutura nas escolas e apoio pedagógico para professores de Biologia, o que reflete no elevado número de evasão escolar. Para superar os desafios, sugere-se a atualização da Proposta Curricular da EJA, na perspectiva de reivindicar políticas públicas visando à garantia da oferta de educação de qualidade aos alunos e professores da EJA que procuram uma nova chance na vida escolar.

Palavras-chave: Ensino de Biologia, EJA, proposta curricular, políticas públicas.
ABSTRACT: The research that based this work had as general objective to analyze the teaching of Biology from the Roraima Curriculum Proposal for Education of Young and Adults - EJA. For the accomplishment of the research the qualitative method was adopted, the data collection was done with the director of DIEJA of the State Department of Education - SEED / RR and with nine professors of Biology. The purpose of the interview was to obtain information about the EJA Curricular Proposal. The questionnaire for teachers aimed to know the professional profile, methods and techniques of teachinglearning. The results showed that the EJA is in a moment of difficulties regarding the offer of working conditions, since it lacks infrastructure in the schools and pedagogical support for teachers of Biology, which reflects in the high number of school dropouts. To overcome the challenges, it is suggested to update the Curriculum Proposal of the EJA, in the perspective of claiming public policies to the educational agencies aiming to guarantee the offer of quality education to the students of the EJA who seek a new chance in school life.

Keywords: Biology Teaching, EJA, curricular proposal,public policy.

1. Graduação em Ciências Biológicas pela Universidade Estadual de Roraima. creonevieira @gmail.com

2. Professora Doutora curso de Ciências Biológicas. sandra@uerr.edu.br 


\section{INTRODUÇÃO}

A educação brasileira, apesar de apresentar boa estrutura teórica e pedagógica fundamentada através de leis modernas, ainda enfrenta enormes dificuldades em oferecer uma educação escolar pública de qualidade.

Tal realidade nos leva aos seguintes questionamentos: A existência de uma Proposta Curricular específica para o ensino da EJA no Estado de Roraima tem contribuído para a melhoria da aprendizagem dos alunos na disciplina biologia? A implantação da Proposta Curricular estabeleceu melhorias na efetivação das políticas públicas na EJA no Estado de Roraima? É importante evidenciar como os docentes de Biologia desenvolvem suas práticas pedagógicas e se essas ações estão em consonância com as finalidades da EJA.

A elaboração da Proposta Curricular da EJA foi coordenada pela Secretaria de Estado de Educação - SEED com a participação democrática de professores e técnicos educacionais. Está organizada em duas partes: a primeira contempla o histórico da EJA no Brasil e Roraima, objetivos, concepções e fundamentos; a segunda referese ao currículo e à matriz curricular da EJA.

A Proposta Curricular da Rede Pública Estadual para a Educação de Jovens e Adultos foi aprovada pelo Parecer $\mathrm{n}^{\circ}$ 017/2011 do Conselho Estadual de Educação do Estado de Roraima CEE-RR, com a finalidade de nortear e orientar a organização pedagógica e servir de suporte pedagógico às escolas, professores e profissionais da EJA.

O objeto de estudo da pesquisa foi a Proposta Curricular do Estado de Roraima para a EJA. O objetivo geral foi analisar o ensino da Biologia a partir da Proposta Curricular de Roraima para a modalidade Educação de Jovens e Adultos - EJA,bem como conhecer as políticas públicas da rede
Estadual de Ensino para a EJA e a contribuição da Proposta Curricular para a melhoria da qualidade do ensino, além evidenciar se os professores de Biologia desenvolvem suas práticas pedagógicas baseadas na Proposta Curricular para essa modalidade de ensino.

Considerando que a Proposta Curricular da EJA,de modo geral, foi uma das reinvindicações dos professores que atuam nesta modalidade, visando à elaboração de um currículo que atendesse as características e especificidades da Educação de Jovens e Adultos, é necessário averiguar se a mesma vem cumprindo a função de atender aos anseios da EJA nas escolas públicas do Estado de Roraima.

\section{BREVE LEVANTAMENTO DA HISTÓRIA DA EDUCAÇÃO DE JOVENS E ADULTOS - EJA}

Em um breve levantamento da história da Educação de Jovens e Adultos no período da Segunda Guerra Mundial, no plano internacional, a Educação de Jovens e Adultos era direcionada à educação formal para os moradores das periferias urbanas e zonas rurais.

De acordo com Gadotti; Romão (2010), a respeito das Conferências Internacionais de Jovens e Adultos - CONFITEA que são realizadas a cada período de 12 anos, em 1949, na I Conferência Internacional de Jovens e Adultos, sediada na Dinamarca, a Educação de Jovens e Adultos foi apresentada com uma educação moral. A escola não foi capaz de evitar a Segunda Guerra Mundial, ou seja, educar o homem para a paz. Por isso, a finalidade era contribuir para o respeito aos direitos humanos e para a construção de uma paz duradoura.

Logo após a II Conferência Internacional, realizada em Montreal no ano de 1963, surgem dois debates sobre Educação de 
Jovens e Adultos, o primeiro representava uma continuação da educação formal, dito como educação permanente, e o segundo, a educação de base ou comunitária.

Ao término da III Conferência Internacional que aconteceu em Tóquio, em 1972, a Educação de Jovens e Adultos passou a ser compreendida como suplência da Educação Fundamental. A finalidade era reintroduzir jovens e adultos, sobretudo no sistema formal de educação.

No ano 1985 aconteceu a IV Conferência Internacional em Paris, que ficou conhecida pela pluralidade de conceitos. Foram discutidos temas sobre alfabetização de adultos, pós-alfabetização, educação rural, educação familiar, educação da mulher, educação em saúde e nutrição, educação cooperativa, educação vocacional e educação técnica.

Para Gadotti (2010), na conjuntura atual, o aluno adulto não pode ser tratado como uma criança cuja história de vida apenas começa. Ele quer ver a aplicação imediata do que está aprendendo. Ao mesmo tempo, apresenta-se temeroso, sente-se ameaçado, precisa ser estimulado, criar autoestima, pois a sua ignorância lhe traz tensão, angústia, complexo de inferioridade. Muitas vezes tem vergonha de falar de si, de sua moradia, de sua experiência frustrada da infância, principalmente em relação à escola. É importante compreender que a realidade do adulto é diferente da realidade da criança, e que isso seja incorporado ao princípio nas nossas metodologias.

\section{PROPOSTA CURRICULAR DA REDE ESTADUAL DE ENSINO PARA A MODALIDADE EDUCAÇÃO DE JOVENS E ADULTOS NO ESTADO DE RORAIMA}

A Proposta Curricular da Rede Estadual de Ensino para a Modalidade Educação de Jovens e Adultos no Estado de Roraima veio atender as garantias estabelecidas na Constituição Federal 1988, na LDB 9.394/96, nos PCNs para essa modalidade de ensino e aos Pareceres e Resoluções dos Conselhos Nacional e Estadual de Educação.

A Proposta é um documento produzido no âmbito do sistema de ensino estadual, como proposta oficial, elaborada em consonância com a atual Lei de Diretrizes e Bases da Educação Nacional (LDBEN 9.394/96), e orientações presentes nos parâmetros e diretrizes curriculares nacionais para a escola básica.

O relatório de análise de propostas curriculares de Ensino Fundamental e Ensino Médio, ao analisar diversas propostas, define o termo da seguinte forma:

$$
\begin{aligned}
& \text { [...] é uma síntese das discussões e reflexões } \\
& \text { de diferentes grupos envolvidos em sua } \\
& \text { elaboração, [...] Para além dos documentos, } \\
& \text { estavam tradições, intenções, interesses, } \\
& \text { histórias de lutas e disputas, relações de } \\
& \text { força, ideias em confronto, enfim, o contexto } \\
& \text { que poderia esclarecer escolhas e caminhos } \\
& \text { abertos para a continuidade do trabalho no } \\
& \text { interior das escolas (BRASIL, 2010, p. 07). }
\end{aligned}
$$

Em 2008, o Governo de Roraima assinou o “Compromisso Todos Pela Educação” e assumiu a responsabilidade de efetivar na sua rede de ensino as diretrizes para a Educação Básica, entre elas, as direcionadas à EJA.

A Proposta foi elaborada em três etapas, na primeira foi instituída uma Coordenação Geral composta por técnicos e professores da área que atuam na modalidade EJA. Essa fase foi marcada por encontros realizados em escolas polos, em que debates e discussões subsidiaram a elaboração do documento preliminar.

Conforme SEED (2011), na segunda parte contou-se com a colaboração de Assessores Técnicos para a redação do documento nos marcos legais e gerais. Dessa maneira, a pedido da Divisão de Educação de Jovens e Adultos, foi necessário elencar uma Consultoria a fim de analisar a Proposta 
Preliminar.

Em seguida constituiu-se uma Comissão formada por professores de cada área que atuam na EJA e técnicos de educação para finalizar a proposta, contemplando os elementos necessários a serem aplicados na modalidade de forma a garantir um documento exequível.

No início de 2011 instituiu-se a Proposta Curricular da Rede Estadual de Ensino para a Modalidade Educação de Jovens e Adultos, divulgada junto às escolas e aos docentes que atuam na modalidade.

Vale ressaltar que este compromisso vai muito além do acesso à escolarização visando à efetividade da aprendizagem. Ou seja, a Proposta para a Educação de Jovens e Adultos tem a finalidade de atender as particularidades dos sujeitos, que esteja em consonância com a legislação atual e norteie a prática pedagógica vivenciada no ambiente escolar.

\section{METODOLOGIA}

A pesquisa teve caráter descritivo, foi desenvolvida durante os meses de outubro a novembro de 2017, o objeto de estudo da pesquisa foi a Proposta Curricular da EJA. A pesquisa foi realizada em duas etapas, a primeira com a diretora da Divisão de Educação de Jovens e Adultos - DIEJA da SEED/RR, a segunda com nove professores de Biologia. Para isso, apresentou-se uma carta de anuência para a diretora da DIEJA solicitando autorização para realização de entrevista gravada em áudio, com 10 perguntas sobre a Proposta Curricular da EJA.

Em seguida foi apresentado aos nove gestores das escolas públicas pesquisadas a Carta de Anuência para autorização de pesquisa e aos nove professores de Biologia o Termo de Consentimento Livre e Esclarecido - TCLE, solicitando a participação na pesquisa. Vale ressaltar que um professor, por motivo pessoal, pediu para não assinar o TCLE, no entanto, verbalmente afirmou que suas respostas poderiam ser utilizadas nos resultados da pesquisa.

Atualmente, na zona urbana do município de Boa Vista existem 18 escolas ofertando a modalidade EJA. Para a oferta da modalidade nessas escolas, a SEED levou em consideração a localização por bairros e o levantamento da demanda das matrículas na EJA.

A técnica da entrevista por meio da gravação de áudio, utilizada no primeiro momento,foi direcionada à diretora da DIEJA, teve como finalidade obter informações sobre a Proposta Curricular da EJA, a situação atual da modalidade de ensino na cidade de Boa Vista - RR, as políticas públicas da rede estadual para a EJA, quantitativos de escolas que ofertam essa modalidade de ensino, suporte pedagógico oferecido às escolas e o acompanhamento da disciplina de Biologia.

No segundo momento, foi aplicado questionário para nove professores no seu local e horário de trabalho, com objetivo de conhecer o perfil profissional, os métodos e técnicas utilizados no processo de ensino e aprendizagem, utilização da Proposta Curricular da EJA através das práticas pedagógicas desenvolvidas em sala de aula, acesso à formação continuada, satisfação com as aulas que ministram, dificuldades encontradas no trabalho docente e avaliação quanto aos conteúdos, relação teoria-prática, material didático e pesquisa.

\section{RESULTADOS E DISCUSSÃO}

Foi constatado que entre os professores pesquisados $89 \%$, ou seja, oito possuem mais de 10 anos de exercício em sala de aula em escolas públicas e $11 \%$ possuem de 1 a 5 anos de experiência profissional,ou seja um professor.Isso é um ponto positivo, pois as experiências podem representar um trabalho 
mais seguro, produtivo e diversificado.

Outro dado importante é que $100 \%$ dos professores pesquisados são concursados e apresentam situação funcional de estabilidade. Este vínculo é essencial para o melhor desempenho das suas atividades docentes.

Quanto à formação acadêmica foram encontrados os seguintes níveis (Gráfico 1). Foi constatado que $100 \%$ dos professores pesquisados são graduados em Ciências Biológicas; $45 \%$ possuem pós-graduação especialização; $22 \%$, mestrado e $11 \%$, doutorado.
No entanto, mesmo com um quadro de professores com currículos bons, a EJA na rede estadual, de acordo com a diretora da DIEJA “apresenta um elevado número de evasão, sendo este um dos maiores problemas".

Constatou-se, a partir da entrevista, que o ensino oferecido aos alunos da EJA precisa melhorar quanto à evasão escolar. Necessitando de acompanhamento, monitoramento e assessoramento pedagógico nas escolas. Nesse caso, são necessárias intervenções urgentes da SEED que visem investigar os reais motivos do abandono escolar, bem como é importante a promoção de políticas públicas que garantam a superação dos problemas existentes e o oferecimento do ensino de qualidade.

A pesquisa mostrou que $65 \%$ dos professores Biologia da EJA estão insatisfeitos com as

Esse resultado é importante, pois sabe-se que a formação e a valorização dos professores são fatores fundamentais para a melhoria da qualidade da educação pública. (Quadro 1).

Quadro 1. Satisfação dos professores com as aulas ministradas na EJA.

\begin{tabular}{|c|c|c|c|}
\hline Prof. & Sim & Năo & Satisfação com as aulas ministradas \\
\hline Prof. A & & $\mathrm{X}$ & Os recursos didáticos são insuficientes. \\
\hline Prof. B & & $\mathrm{X}$ & $\begin{array}{l}\text { Gostaria que tivesse estrutura na escola para aulas práticas de campo e } \\
\text { laboratório. O conhecimento se faz com práxis, precisamos mostrar para o } \\
\text { aluno a contextualização dos conteúdos e sair do mundo das idealizações } \\
\text { para o mundo real. }\end{array}$ \\
\hline Prof. $\mathrm{C}$ & $\mathrm{X}$ & & Apesar dos poucos métodos utilizados, estou satisfeito. \\
\hline Prof. D & $\mathrm{X}$ & & $\begin{array}{l}\text { Precisamos de mais apoio pedagógico para o desenvolvimento de } \\
\text { trabalhos e projetos. }\end{array}$ \\
\hline Prof. E & $\mathrm{X}$ & & Sim, estou satisfeito, mas toda mudança deve ser acolhida. \\
\hline Prof. F & & $\mathrm{X}$ & $\begin{array}{l}\text { Necessita de material para os alunos, livros e apostila. Nem sempre é } \\
\text { possível aquisição de cópias por eles. }\end{array}$ \\
\hline Prof. G & & $\mathrm{X}$ & $\begin{array}{l}\text { Seria de grande valia se tivesse um laboratório na escola, pois nossas } \\
\text { condições para aplicabilidade de experimentos são bastante precária. } \\
\text { Também os livros didáticos são insuficientes para auxiliar no } \\
\text { desenvolvimento. }\end{array}$ \\
\hline Prof. H & & $\mathrm{X}$ & $\begin{array}{l}\text { Gostaria de mais auxilio. Quando quero fazer algo diversificado, tenho que } \\
\text { comprar os materiais para poder diversificar. }\end{array}$ \\
\hline Prof. I & & $\mathrm{X}$ & $\begin{array}{l}\text { Gostaria mais recursos para trabalhar as aulas de biologia, não temos } \\
\text { livros. Agora que a escola está organizando uma sala de video. }\end{array}$ \\
\hline
\end{tabular}


$\mathrm{O}$ professor $\mathrm{H}$ revelou que gostaria de mais auxílio, pois quando deseja proporcionar aulas diversificadas, o mesmo necessita comprar os materiais com recursos próprios. Essa informação é muito preocupante, considerando que a responsabilidade de manutenção das escolas é do poder público. pedagógicos da EJA. A Proposta como resultado de discussãoe reflexão de grupos, se bem implementada representa uma ferramenta norteadora da prática pedagógica.

Em seguida foi perguntado se o professor utiliza a Proposta da EJA como instrumento inserido em seu cotidiano docente, no planejamento e na execução das atividades.

Quadro 2. Utilização da Proposta da EJA pelos professores.

\begin{tabular}{|c|c|}
\hline Professores & Utilização da Proposta da EJA \\
\hline Professor $A$ & “utiliza a Proposta Curricular da EJA por intermédio do planejamento". \\
\hline Professor $B$ & $\begin{array}{l}\text { "faço o planejamento das aulas, conforme a Proposta Curricular da EJA, procurando } \\
\text { trazer para a realidade da escola". }\end{array}$ \\
\hline Professor $B$ & "não conhece a Proposta Curricular da EJA". \\
\hline Professor $C$ & "baseando no planejamento direcionado". \\
\hline Professor D & $\begin{array}{l}\text { "conhece a Proposta Curricular da EJA, porém não fez suas considerações quanto ao } \\
\text { uso". }\end{array}$ \\
\hline Professor E & "utilizo para nortear o plano de ensino". \\
\hline Professor $F$ & $\begin{array}{l}\text { "Proposta Curricular da EJA verificamos que é de suma importância as relações } \\
\text { interdisciplinares, trabalhando em coletivo, tentando interagir e inserir o aluno como } \\
\text { um todo para obter um resultado satisfatório no resgate educacional”. }\end{array}$ \\
\hline Professor $H$ & $\begin{array}{l}\text { "conhece a Proposta Curricular da EJA, mas prefere trabalhar com adaptações, pois } \\
\text { não concorda com a Proposta". }\end{array}$ \\
\hline Professor I & "não conhece a Proposta Curricular da EJA". \\
\hline
\end{tabular}

Uma sugestão importante para a melhoria do processo ensino e aprendizagem é a Proposta Curricular da EJA, a DIEJA confirmou a existência da Proposta Curricular da EJA, aprovada pelo Parecer $\mathrm{n}^{\circ}$ 017/2011 do Conselho Estadual de Educação de Roraima - CEE/RR. Segundo a diretora da DIEJA, o fluxo de lotação dos professores nas escolas têm dificultado uma implementação de forma significativa da Proposta Curricular da EJA.

Quanto ao conhecimento dos professores de Biologia em relação à Proposta Curricular da EJA, dos nove participantes da pesquisa, 07responderam que conhecem e 02 responderam que não. Respectivamente $78 \%$ sim e $22 \%$ não, no entanto, como informado pela diretora da DIEJA e pelos próprios professores, há um elevado número de evasão escolar. Compreende-se que somente o conhecimento da Proposta não resolve os problemas
Observou-se que apenas $56 \%$ dos professores de Biologia responderam que utilizam a Proposta Curricular da EJA como instrumento inserido no planejamento e na execução das atividades, $44 \%$ responderam que não utilizam a Proposta da EJA na elaboração do planejamento.

Para a DIEJA, a oferta da Educação de Jovens e Adultos é de fundamental importância ao suprir a falta de escolaridade desse público e também como forma de aceleração para os alunos fora da faixa etária vindos do ensino regular. Assim, a Proposta atende aos anseios dessa demanda, porém não vem cumprindo sua finalidade de nortear e orientar a organização pedagógica e servir de suporte aos profissionais que atuam nesta modalidade de ensino, para que esse trabalho pudesse ser revertido em melhorias no processo de ensino e aprendizagem. Após seis anos de implantação a Proposta Curricular da EJA ainda não é conhecida por 
todos os professores que atuam nessa modalidade de ensino.

Para a diretora da DIEJA “alguns professores querem planejar apenas dentro da sua área específica, em detrimento da Proposta, eles esquecem que precisam conhecer o que eles vão trabalhar”. A DIEJA vem passando por falta de apoio e estrutura que interfere na quantidade e na qualidade dos trabalhos de norteamento, orientação pedagógica e suporte aos profissionais que atuam na EJA. Outro ponto ressaltado por esta divisão foi a falta de comunicação com as escolas, que enviam o calendário escolar, e muitas vezes sofrem alterações ao longo do semestre letivo, sem prévia comunicação, dificultando a participação dos técnicos nas ações das escolas.

Na Proposta Curricular da EJA, um dos princípios para educação é [...] Possibilitar ao aluno a aquisição de habilidades que permitam organizar e estruturar, de forma articulada, os temas sociais, os conceitos e os conteúdos associados à formação humanosocial.[...] (SEED, 2011, p. 23). Assim,constata-se a intenção da Proposta em garantir aos alunos aprendizagem pautada nas especificidades da EJA. subsidia a formação de competências e habilidades, a partir do trabalho de conteúdos associados à formação humanosocial, através de abordagem de situações reais. A DIEJA afirmou que não recebeu críticas dos professores sobre a Proposta. Porém, foi criticada por parte dos coordenadores pedagógicos que consideram a leitura de difícil compreensão, omitindo informações importantes sobre a estrutura e funcionamento da modalidade EJA, a exemplo, o único trecho que cita o curso da EJA com duração semestral é quando menciona a frequência mínima semestral, ocasionando dúvidas na prática. Outro fato é que muitos professores têm a carga horária de trabalho distribuída em mais de um turno. Isso dificulta o conhecimento da Proposta, contribuindo para que os mesmos utilizem os conteúdos e as metodologias do ensino regular na EJA, desconsiderando as especificidades dos alunos dessa modalidade de ensino.

Em relação aos métodos e técnicas de ensino-aprendizagem utilizados em sala de aula pelos professores de Biologia constatouse que $19 \%$ utilizam seminários como método de ensino (Gráfico 2).

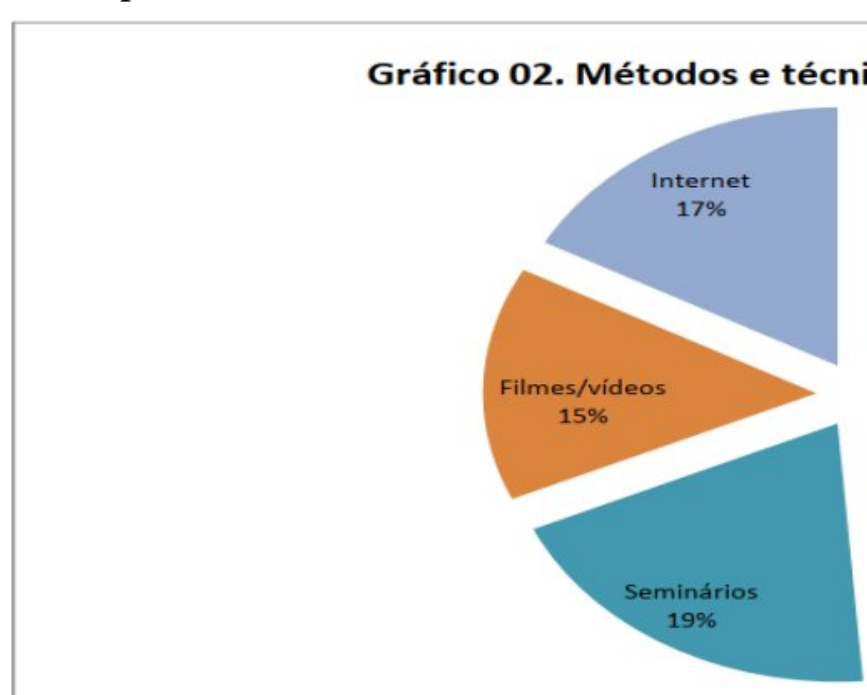

icas de ensino-aprendizagem

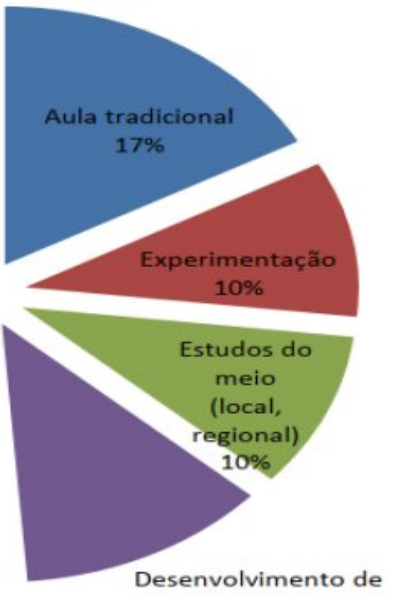

projetos

$12 \%$

Dessa, forma a Proposta Curricular da EJA oferece um referencial teórico que
Identificou-se que 15\% dos professores utilizam filmes e vídeos para oferecer aulas 
atrativas e interessantes; $17 \%$ realizam pesquisa na internet com os alunos; $17 \%$ se utilizam de aulas tradicionais; 12\% trabalham com desenvolvimento de projetos; $10 \%$ trabalham com estudos do meio e outros $10 \%$ trabalham com experimentação.

Em relação a avaliação do ensino de Biologia na EJA, levando em consideração os conteúdos, à relação teoria-prática, material didático e pesquisa, obteve-se os resultados expostos no Quadro 3.
O primeiro critério de avaliação do ensino de Biologia foi quanto aos conteúdos, $100 \%$ dos professores compartilham que o tempo reduzido dificulta o trabalho dos conteúdos.O professor $\mathrm{G}$ disse que, "apesar do tempo reduzido, consegue trabalhar os conteúdos, o professor I falou que os conteúdos devem ser sucintos, devido os alunos apresentarem dificuldades, pois a maioria voltou a estudar depois de muito tempo". O professor E respondeu que, "os conteúdos são os mesmos do regular”. É

Quadro 3. Avaliação do ensino de Biologia na EJA pelos professores.

\begin{tabular}{|c|c|c|}
\hline Critérios & Prof. & Avaliações \\
\hline \multirow[t]{9}{*}{ Conteúdos } & Prof. A & Os conteúdos são suficientes, porém, às vezes o tempo não é. \\
\hline & Prof. B & Tempo muito corrido, o que compromete os conteúdos. \\
\hline & Prof. C & Tempo insuficiente para passar os conteudos do semestre. \\
\hline & Prof. D & Pouco tempo de trabalho para ministrar o minimo necessário. \\
\hline & Prof. E & Os conteúdos são os mesmos do regular: \\
\hline & Prof. F & Pouco tempo para ser ministrados. \\
\hline & Prof. G & Apesar do tempo reduzido, os conteudos dão de ser trabalhados. \\
\hline & Prof. $\mathrm{H}$ & Pouco tempo para ministrar os conteudos propostos. \\
\hline & Prof. I & $\begin{array}{l}\text { Devem ser sucintos, os alunos apresentam muitas dificuldades, a } \\
\text { maioria voltou a estudar depois de muito tempo. }\end{array}$ \\
\hline \multirow{9}{*}{$\begin{array}{l}\text { Teoria- } \\
\text { prática }\end{array}$} & Prof. A & Os laboratórios são insuficientes. \\
\hline & Prof. B & É Preciso melhorar os espaços da escola. \\
\hline & Prof. C & Não há tempo hábil para a prática em laboratório. \\
\hline & Prof. D & Pouco tempo para pôr em prática as atividades explanadas. \\
\hline & Prof. E & Ensinar teoria e prática auxilia muito. \\
\hline & Prof. F & $\begin{array}{l}\text { Quando ocorre é no laboratório, aula de campo é complicado pelo } \\
\text { horário, transporte e tempo. }\end{array}$ \\
\hline & Prof. G & $\begin{array}{l}\text { A falta de estrutura fisica, de materiais e equipamentos deixam a } \\
\text { desejar temos apoio dos estagiários do PIBID. }\end{array}$ \\
\hline & Prof. $\mathrm{H}$ & Para funcionar temos que levar todos os materiais. \\
\hline & Prof. I & Quase sempre ficamos apenas na teoria. \\
\hline \multirow{9}{*}{$\begin{array}{l}\text { Material } \\
\text { didático }\end{array}$} & Prof. A & São poucos, mas a tecnologia pode mudar isso. \\
\hline & Prof. B & Temos que financiar o material. \\
\hline & Prof. C & Material fraco, baixa qualidade. \\
\hline & Prof. D & Uso Datashow, filmes, biblioteca e internet. \\
\hline & Prof. E & Os alunos não recebem nada. \\
\hline & Prof. F & O material que usamos em si é pouco \\
\hline & Prof. G & A Educação não funciona, os livros estão fora dos contextos. \\
\hline & Prof. $\mathbf{H}$ & $\begin{array}{l}\text { Os conteúdos são abordados no quadro, ou os alunos compram } \\
\text { apostila. }\end{array}$ \\
\hline & Prof. I & A SEED deveria providenciar material didático para a EJA. \\
\hline \multirow[t]{9}{*}{ Pesquisa } & Prof. A & A senha do laboratório de informática não é socializada. \\
\hline & Prof. B & Devemos valorizar a pesquisa como ferramenta didática. \\
\hline & Prof. C & Não há pesquisa. \\
\hline & Prof. D & Falta de tempo dos alunos para desenvolvimento das mesmas. \\
\hline & Prof. E & Montamos projetos e cobramos as normas $A B N T$. \\
\hline & Prof. F & Pouco desenvolvida pelo segmento. \\
\hline & Prof. G & $\begin{array}{l}\text { Na escola não temos laboratório de informática e devido à situação } \\
\text { econômica e social dos alunos dificulta os resultados. }\end{array}$ \\
\hline & Prof. $\mathrm{H}$ & Laboratório com poucos computadores, internet muito fraca. \\
\hline & Prof. I & Ainda não realizei pesquisa cientifica com os meus alunos. \\
\hline
\end{tabular}


necessário enfatizar a importância do professor privilegiar a qualidade do ensino de Biologia.

Quanto à avaliação da teoria-prática, quatro professores afirmaram que a falta de estrutura e de equipamentos nas escolas dificulta o desenvolvimento das aulas práticas. Três professores afirmaram que o tempo reduzido na EJA dificulta a realização de aulas práticas, um professor citou a importância de ensinar teoria e prática e apenas um respondeu que trabalha predominantemente a teoria.

Em relação ao material didático, pôde-se constatar que os professores da EJA enfrentam sérias dificuldades para a internet ruim. O professor $\mathrm{C}$ respondeu, "falta de tempo", sabemos que a melhoria da educação pública requer investimento significativo na educação, oferecendo condições de trabalho ao professor.

De acordo com o exposto acima, constatou-se o compromisso dos professores pesquisados em oferecer aulas atrativas, produtivas e de qualidade, porém, a falta de apoio e de estrutura das escolas dificulta a ocorrência dessas práticas.

Quanto às dificuldades encontradas no trabalho docente, $89 \%$ dos professores relatam encontrar dificuldades no trabalho docente (Quadro 4).

A respeito das dificuldades apenas 0

Quadro 4. Dificuldades no trabalho docente na EJA.

\begin{tabular}{|c|l|}
\hline Professor & \multicolumn{1}{c|}{ Dificuldades no trabalho docente na EJA } \\
\hline Professor A & $\begin{array}{l}\text { A maior barreira é na execução do planejamento, ocorrem muitos imprevistos e } \\
\text { improvisos. }\end{array}$ \\
\hline Professor B & $\begin{array}{l}\text { Existem problemas estruturais: ainda falta no contexto escolar da realidade da } \\
\text { EJA, o planejamento integrado entre as disciplinas. Pois na verdade poderiamos } \\
\text { estabelecer um diálogo entre os conteúdos das disciplinas como forma de mostrar } \\
\text { aos alunos que o mundo do conhecimento pode seguir a lógica da integração. }\end{array}$ \\
\hline Professor C & $\begin{array}{l}\text { Falta de compromisso dos alunos, distancia da casa para o colégio. Isso faz com } \\
\text { que muitos desistam. Existe uma evasão muito grande, isso desmotiva o professor. }\end{array}$ \\
\hline Professor D & Falta de interesse dos alunos, falta de material de apoio e o tempo muito reduzido. \\
\hline Professor E & Não há dificuldades. \\
\hline Professor F & Indisponibilidade de tempo dos alunos, falta de tempo e falta de material. \\
\hline Professor G & $\begin{array}{l}\text { Os alunos devido à grande maioria trabalhar durante o dia, temos uma variação } \\
\text { de infrequência escolar. O qual tentamos todo o ano combater esse fato. }\end{array}$ \\
\hline Professor H & Falta de laboratório, de internet de qualidade, de livros especificos para a EJA. \\
\hline Professor I & $\begin{array}{l}\text { Temos pouca atenção quanto à formação, plano amual, metodologia. Não temos } \\
\text { muito acompanhamento da SEED. }\end{array}$ \\
\hline
\end{tabular}

realização dos trabalhos. $\mathrm{O}$ professor $\mathrm{C}$ professor $\mathrm{E}$ relatou "não encontrar afirmou "temos que comprar o material". dificuldades". O professor A citou "barreiras Nesse contexto, a Educação de Jovens e na execução do planejamento, ocorrem Adultos requer mais atenção das autoridades muitos imprevistos”. O professor G públicas.

Sobre a utilização da pesquisa como ferramenta de aprendizagem na EJA, verificou-se que dois professores afirmastes trabalhar com pesquisa. No entanto, sete não trabalham com pesquisa na EJA, pontuando as dificuldades do não funcionamento do laboratório de informática, senha não compartilhada, poucos computadores e respondeu que "os alunos, devido à maioria trabalhar durante o dia, temos uma variação de infrequência escolar”. O professor I citou “ pouca atenção quanto à formação continuada, plano anual e metodologia, não temos muito acompanhamento da SEED". Isso corrobora com o que a diretora da DIEJA respondeu sobre a falta de visitas técnicas nas escolas por falta de recursos. 
Tratando da oferta de cursos de formação continuada promovidos pela DIEJA para os professores de Biologia ou por área de conhecimento, $56 \%$ dos professores responderam que a formação continuada aos professores é uma ação essencial na qualificação e aperfeiçoamento profissional. Sobre a importância da formação continuada dos professores, na Proposta da EJA existe o artigo $\mathrm{n}^{\circ} 61$ da LDB $\mathrm{N}^{\circ}$ 9394/96 que deve ocorrer preferencialmente no espaço escolara formação dos profissionais da educação, de modo a atender às especificidades do exercício de suas atividades, bem como aos objetivos das diferentes etapas e modalidades da educação básica (SEED,2011, p. 38). A falta de estudos da Proposta Curricular da EJA nos encontros pedagógicos e nas formações continuadas contribui para a não efetivação da Proposta na prática.

Sobre a existência de acompanhamento do processo ensino e aprendizagem em Biologia, a DIEJA informou que atualmente não existe esse tipo de acompanhamento por disciplina ou por área de conhecimento por parte desta divisão.

Constatou-se que a DIEJA não está conseguindo realizar os acompanhamentos das atividades, in loco, desenvolvidas nas escolas, a saber: as devolutivas dos quadros de rendimento escolar, do cumprimento da entrega do planejamento de ensino e do acompanhamento da execução das disciplinas e dos componentes curriculares. A divisão informou que as escolas realizam o acompanhamento dos trabalhados das disciplinas através dos registros das aulas nos diários de classe, atas dos encontros pedagógicos e conselho de classe, em que são discutidas as situações do rendimento de cada aluno. Contudo, é muito preocupante que as escolas não estejam recebendo esse tipo de acompanhamento por parte da DIEJA.
Sobre a verificação do Rendimento Escolar, na Proposta da EJA a avaliação do processo de ensino e aprendizagem objetiva diagnosticar a situação de cada aluno, bem como ação pedagógica do docente (SEED, 2011, p. 61). Sobre as necessidades de orientações metodológicas no ensino de Biologia, a Proposta da EJA, apresenta que:

No ensino de Biologia é necessária a
intervenção planejada do professor,
propiciando situações de aprendizagem
significativa, com experimentações,
observações, análises, questionamentos e
interpretações que levem a construção do
conhecimento biológico. A intervenção do
docente deve, portanto oportunizar aos alunos
situações didáticas que leve-os a observar
determinado fato, identificar problemas e
elaborar respostas (SEED, 2011, p. 212).

Em relação às políticas públicas existentes para a EJA, para os próximos anos foi assinado um termo de Cooperação com o Instituto Federal de Roraima - IFRR para o oferecimento de 60 vagas no curso de Pós Graduação em Especialização específica para os professores lotados na Educação de Jovens e Adultos. A DIEJA também é a responsável no Estado, para coordenar e aplicar a Prova do ENCCEJA que é o Exame Nacional para Certificação de Competências de Jovens e Adultos.

Também aguarda a reabertura do Centro de Educação de Jovens e Adultos do Estado de Roraima - CEJARR, que atenderá nos modos presencial, semi-presencial e Exames de suplência com horários de funcionamento matutino, vespertino e noturno, que terá capacidade para atender os alunos Portadores de Necessidades Educacionais - PNE que atualmente sentem-se excluídos por não conseguirem estudar no horário noturno.

\section{CONSIDERAÇÕES FINAIS}

Na DIEJA, confirmou-se que desde 2011, o Estado de Roraima possui a Proposta Curricularda EJA com o objetivo de nortear e orientar a organização pedagógica e servir de suporte pedagógico aos profissionais que atuam nessa modalidade de ensino. 
Verificou-se que foi instituído um calendário que contemplava a avaliação e atualização da Proposta Curricular da EJA a cada período de 2 anos, porém desde a sua implementação não foi atualizada e, portanto, não atende de forma significativa as finalidades para a realidade atual. Atualmente existe uma Comissão Técnica da DIEJA trabalhando na atualização da Proposta que contará com o envolvimento dos professores lotados na EJA.

Nas declarações da DIEJA, constatou-se que muitas intercorrências encontradas na Proposta Curricular da EJA poderiam ter sido evitadas se a mesma tivesse recebido as devidas avaliações de aplicabilidade junto aos professores, conforme previsto no planejamento do processo de implantação, desenvolvimento e implementação.

Ressalta-se queas práticas citadas pelos professoresestão em consonância com a Proposta Curricular da EJA, apresentadas como sugestões teóricas sobre a utilização de recursos pedagógicos para um ensino que coloque o aluno como centro de sua aprendizagem.

A existência da Proposta Curricular é de fundamental importância como ferramenta estabelecedora das políticas públicas na EJA, além de proporcionar uma melhor organização do currículo, da metodologia e dos objetivos, compreendendo que a modalidade de ensino EJA é diferente do ensino regular, às vezes, na prática, sofre resistência por parte dos professores. No entanto, a Proposta Curricular da EJA não resolve todos os problemas dessa modalidade de ensino. E não foi o suficiente para garantir uma mudança expressiva na EJA. Há uma diferença entre o que foi idealizado e o ensino real praticado nas escolas. São necessários investimentos na infraestrutura das escolas e no acesso a melhores condições de trabalho aos professores.
Diante docontexto ao longo tempo, a Educação de Jovens e Adultos no Governo Federal e Estadual esteve, na maior parte do tempo, relegada a segundo plano pelas políticas governamentais. Há a necessidade efetiva de garantir direitos a essa modalidade da educação visando políticas de educação capazes de estruturar e organizar o ensino, metodologias educacionais e de gestão.

Superados esses desafios, espera-se que as pessoas envolvidas da Educação de Jovens e Adultosreflitam sobre aimportância social da sua função, no enfrentamento à exclusão e às desigualdades educacionais e sociais e possam contribuir na construção de uma sociedade mais justa, solidária e democrática.

\section{REFERÊNCIAS}

BRASIL. Senado Federal. Lei de Diretrizes e Bases da Educação Nacional: $n^{\circ}$ 9394/96. Brasília: 1996.

GADOTTI, Moacir; ROMÃO, José E. (Orgs). GUIA DA ESCOLA CIDADÃO, Instituto Paulo Freire. Educação de Jovens e Adultos. Teoria, prática e proposta. 10 ed. Rio de Janeiro: Cortez, 2008.

GIL, Antonio Carlos. Métodos e técnicas de pesquisa social. 6 ed. - São Paulo: Atas, 2008.

RORAIMA. Proposta Curricular da Rede Estadual de Ensino para a Modalidade Educação de Jovens e Adultos. Boa Vista/RR, Brasil, 2011. 